\title{
Clinical Study \\ Beneficial Effect of Low-Fat Elemental Diet Therapy on Pain in Chronic Pancreatitis
}

\author{
Tsukasa Ikeura, Makoto Takaoka, Kazushige Uchida, \\ Hideaki Miyoshi, and Kazuichi Okazaki \\ The Third Department of Internal Medicine, Kansai Medical University, 2-3-1 Shinmachi, Hirakata, Osaka 573-1191, Japan \\ Correspondence should be addressed to Tsukasa Ikeura; ikeurat@hirakata.kmu.ac.jp
}

Received 17 December 2013; Accepted 25 March 2014; Published 14 April 2014

Academic Editor: Richard E. Kast

Copyright (C) 2014 Tsukasa Ikeura et al. This is an open access article distributed under the Creative Commons Attribution License, which permits unrestricted use, distribution, and reproduction in any medium, provided the original work is properly cited.

Background \& Aims. Chronic pancreatitis (CP) is often associated with abdominal pain, which impairs quality of life. The aim of this prospective study was to clarify whether the use of a low-fat elemental diet (ED) is beneficial for managing pain in patients with CP. Methods. Seventeen CP patients with pain despite fat-restricted dietary and conventional medical treatments were enrolled in this prospective study. These patients received low-fat ED therapy in addition to restricting fat intake for 8 weeks. The change of pain severity was examined by interviewing the patient and status of analgesic use. Results. Mean serum levels of amylase and lipase at 8 weeks after the beginning of low-fat ED therapy decreased compared to those before the therapy. At 8 weeks, pain alleviation after low-fat ED therapy was reported in 15 out of 17 patients $(88 \%)$. Of these 15 patients, 10 patients reported complete pain disappearance. One of 3 patients with severe or moderate pain requiring analgesic was relieved of analgesic use after low-fat ED therapy. Conclusion. Low-fat ED therapy is useful as means of pain control in CP. The therapy is recommended in outpatients with CP who present with pain despite conventional dietary and medical treatments.

\section{Introduction}

Chronic pancreatitis $(\mathrm{CP})$ is characterized histologically by the destruction of acinar cells and presence of irregular fibrosis within the pancreas. Most patients with $\mathrm{CP}$ have abdominal pain, maldigestion, and diabetes mellitus $[1,2]$. The most frequent and serious clinical symptom is abdominal pain, which occurs in at least $75 \%$ of patients suffering from CP [3]. The recurrent or protracted abdominal pain in CP is often difficult to manage and decreases patients' quality of life. Pain management in CP includes dietary treatment (e.g., fat restriction and cessation of alcohol and tobacco use), medical treatment (e.g., analgesics, high-dose pancreatic enzymes, and acid suppression agents), endoscopic treatment (e.g., sphincterotomy, lithotripsy, and pancreatic duct stenting), and surgery. American Gastroenterological Association guidelines recommend a low-fat diet as the initial management for the pain in CP [4].

It is well known that an elemental diet (ED) has a protective effect in patients suffering from Crohn's disease [5]. ED has the following features: (1) the digestion of protein by pancreatic enzymes is not required because nitrogen is derived from amino acids alone; (2) ED contains minimal fat. A recent paper by Ito et al. showed 2 patients in whom the oral administration of a low-fat ED (Elental; Ajinomoto Pharmaceutical Ltd., Tokyo, Japan) was useful for alleviating pain in CP [6]. We conjecture that this beneficial effect results from "pancreas rest" due to the extremely small amount of fat in the diet.

To the best of our knowledge, no additional survey has confirmed the utility of low-fat ED therapy in CP patients with pain. The aim of this prospective study was to clarify whether the use of a low-fat ED is beneficial for managing pain in patients with $\mathrm{CP}$.

\section{Materials and Methods}

2.1. Patients. Patients with $\mathrm{CP}$ who presented with pain despite fat-restricted dietary and conventional medical treatments were enrolled in this prospective study between 2009 and 2012. Patients who had undergone past endoscopic and 
surgical interventions were excluded from this study. All patients underwent routine laboratory tests and imaging studies including ultrasonography, computed tomography, and magnetic resonance cholangiopancreatography. In some patients, additional examinations such as pancreatic exocrine function test (the $\mathrm{N}$-benzoyl-L-tyrosyl-p-aminobenzoic acid test) [7], endoscopic ultrasonography, and endoscopic retrograde cholangiopancreatography were performed. Using the findings of these examinations, the diagnosis of $\mathrm{CP}$ (definitive, probable, early, and possible) was established according to the clinical diagnostic criteria proposed by the Japan Pancreas Society [8].

2.2. Study Protocol. After obtaining informed consent, their clinical data (sex, age, etiology of $\mathrm{CP}$, smoking habit, and diabetes status) were recorded. Information about concurrent medications such as analgesics, pancreatic enzymes, acid suppression agents, and protease inhibitors was also collected.

Low-fat ED therapy was performed on an outpatient basis using Elental, which is commercially available in Japan. This powdered formula contains $79.3 \%$ dextrin, $17.6 \%$ amino acids, $0.6 \%$ soybean oil, $2.0 \%$ minerals, and $0.5 \%$ vitamins, by weight (Table 1) $[9,10]$. The patients were instructed to take at least 1 packet $(80 \mathrm{~g})$ of Elental per day in addition to restricting their fat intake. A packet of Elental was dissolved in $300 \mathrm{~mL}$ of lukewarm water for an eventual concentration of $1 \mathrm{kcal} / \mathrm{mL}$.

Pain severity was assessed at 0 weeks (at the beginning of the low-fat ED therapy) and at 4 and 8 weeks (after the initiation of therapy) by performing patient interviews and assessing the status of analgesic use. Pain degree was graded according to 3 levels as follows: grade 2, severe or moderate pain requiring analgesics; grade 1 , mild pain not requiring analgesics; and grade 0, no pain. Moreover, we determined the serum levels of amylase, lipase, total protein, and albumin and evaluated the adverse events at 0,4 , and 8 weeks.

2.3. Definitions. CP was classified into 2 distinct categories according to etiology: alcoholic and nonalcoholic. Alcoholic CP was diagnosed in patients with a daily intake of pure alcohol $>80 \mathrm{~g}$ for at least 5 years. Nonalcoholic CP included idiopathic CP and CP induced by other etiological factors, including neoplasm and congenital anomaly [7]. The diagnosis of diabetes was defined as a fasting glucose level $>127 \mathrm{mg} / \mathrm{dL}(7 \mathrm{mmol} / \mathrm{L})$ or a glucose level $>201 \mathrm{mg} / \mathrm{dL}$ (11 mmol/L) 2 hours after a glucose load [11].

2.4. Statistical Analysis. Differences among groups were analyzed using Student's $t$-test for quantitative variables. A $P$ value $<0.05$ was considered statistically significant.

\section{Results}

Nineteen patients with CP were prospectively registered in this study. However, 2 patients were excluded from the study: 1 patient with diabetes showed aggravated glycemic control at 4 weeks after the initiation of ED therapy, and another patient was lost to follow-up. Accordingly, a total of 17 patients
TABLE 1: Ingredients of Elental (total $100 \mathrm{~g}$ ).

\begin{tabular}{|c|c|}
\hline Amino acids & $17.6 \mathrm{~g}$ \\
\hline L-Isoleucine & $803 \mathrm{mg}$ \\
\hline L-Leucine & $1124 \mathrm{mg}$ \\
\hline L-Lysine-HCl & $1110 \mathrm{mg}$ \\
\hline L-Methionine & $810 \mathrm{mg}$ \\
\hline L-Phenylalanine & $1089 \mathrm{mg}$ \\
\hline L-Threonine & $654 \mathrm{mg}$ \\
\hline L-Tryptophan & $189 \mathrm{mg}$ \\
\hline L-Valine & $876 \mathrm{mg}$ \\
\hline L-Histidine- $\mathrm{HCl}-\mathrm{H}_{2} \mathrm{O}$ & $626 \mathrm{mg}$ \\
\hline L-Arginine- $\mathrm{HCl}$ & $1406 \mathrm{mg}$ \\
\hline L-Alanine & $1124 \mathrm{mg}$ \\
\hline Mg-K-L-Aspartate & $1295 \mathrm{mg}$ \\
\hline $\mathrm{Na}-\mathrm{L}$-Aspartate- $\mathrm{H}_{2} \mathrm{O}$ & $1084 \mathrm{mg}$ \\
\hline L-Glutamine & $2415 \mathrm{mg}$ \\
\hline Glycine & $631 \mathrm{mg}$ \\
\hline L-Proline & $788 \mathrm{mg}$ \\
\hline L-Serine & $1449 \mathrm{mg}$ \\
\hline L-Tyrosine & $138 \mathrm{mg}$ \\
\hline Carbohydrate (dextrin) & $79.3 \mathrm{~g}$ \\
\hline Lipid (soybean oil) & $0.6 \mathrm{~g}$ \\
\hline Vitamin A & $810 \mathrm{IU}$ \\
\hline Vitamin D & $64 \mathrm{IU}$ \\
\hline Vitamin B1 & $0.24 \mathrm{mg}$ \\
\hline Vitamin B2 & $0.25 \mathrm{mg}$ \\
\hline Vitamin B6 & $0.33 \mathrm{mg}$ \\
\hline Niacin & $2.78 \mathrm{mg}$ \\
\hline Pantothenic acid & $1.38 \mathrm{mg}$ \\
\hline Folic acid & $55 \mu \mathrm{g}$ \\
\hline Vitamin B12 & $0.88 \mu \mathrm{g}$ \\
\hline Vitamin C & $9.75 \mathrm{mg}$ \\
\hline Vitamin K & $11.3 \mu \mathrm{g}$ \\
\hline Vitamin E & $4.13 \mathrm{IU}$ \\
\hline Biotin & $48.8 \mu \mathrm{g}$ \\
\hline Choline & $10.7 \mathrm{mg}$ \\
\hline $\mathrm{Na}$ & $325 \mathrm{mg}$ \\
\hline $\mathrm{K}$ & $272 \mathrm{mg}$ \\
\hline $\mathrm{Cl}$ & $646 \mathrm{mg}$ \\
\hline $\mathrm{Mg}$ & $50 \mathrm{mg}$ \\
\hline $\mathrm{Ca}$ & $197 \mathrm{mg}$ \\
\hline $\mathrm{P}$ & $152 \mathrm{mg}$ \\
\hline $\mathrm{Fe}$ & $2.25 \mathrm{mg}$ \\
\hline I & $19 \mu \mathrm{g}$ \\
\hline $\mathrm{Mn}$ & $375 \mu \mathrm{g}$ \\
\hline $\mathrm{Cu}$ & $250 \mu \mathrm{g}$ \\
\hline $\mathrm{Zn}$ & $2.25 \mathrm{mg}$ \\
\hline
\end{tabular}

( 4 males and 13 females; mean age, $49.8 \pm 11.7$ years) were studied (Table 2). Alcoholic and nonalcoholic CP were observed in 4 patients (24\%) and 13 patients (76\%), respectively. The etiologies of nonalcoholic CP were idiopathic in 11 patients $(65 \%)$, pancreas divisum in 1 patient $(6 \%)$, and 
TABLE 2: Characteristics of analyzed patients.

\begin{tabular}{lc}
\hline & All patients $(n=17)$ \\
\hline Gender & $4(24 \%)$ \\
Male & $13(76 \%)$ \\
Female & $49.8 \pm 11.7$ \\
Age (mean \pm SD) & $3(18 \%)$ \\
Smokers & \\
Etiology & $13(76 \%)$ \\
Nonalcoholic & $4(24 \%)$ \\
Alcoholic CP & \\
Diagnosis by Japanese diagnostic criteria & $2(12 \%)$ \\
Definitive CP & $15(88 \%)$ \\
Possible CP & \\
Medication & $13(76 \%)$ \\
Acid suppression agents & $10(59 \%)$ \\
Pancreatic enzymes & $9(53 \%)$ \\
Protease inhibitors & $3(18 \%)$ \\
Analgesics & $1(6 \%)$ \\
Diabetes & \\
Dosage amount of Elental per day & $10(59 \%)$ \\
80 g & $3(18 \%)$ \\
160 g & $4(23 \%)$ \\
\hline
\end{tabular}

intraductal papillary mucinous neoplasm in 1 patient $(6 \%)$. Two patients (12\%) were diagnosed as definitive CP and 15 patients $(88 \%)$ as probable CP according to the Japanese diagnostic criteria for CP. Prior to the initiation of lowfat ED therapy, 15 patients $(88 \%)$ were treated with other medical therapies for pain, including acid suppression agents in 13 patients (76\%), pancreatic enzymes in 10 patients (59\%), protease inhibitor, that is, camostat mesilate, in 9 patients (53\%), and analgesics in 3 patients (18\%). Diabetes was observed in 1 patient (6\%), who was treated with glimepiride. One packet $(80 \mathrm{~g})$ of Elental per day was taken by 10 patients (59\%), 2 packets $(160 \mathrm{~g})$ by 3 patients $(18 \%)$, and 3 packets ( $240 \mathrm{~g})$ by 4 patients $(23 \%)$.

Mean serum levels of amylase and lipase at 8 weeks after low-fat ED therapy decreased compared to those at 0 weeks (amylase, $48 \pm 27.2 \mathrm{IU} / \mathrm{L}$ at 0 weeks versus $38.8 \pm 13.5 \mathrm{IU} / \mathrm{L}$ at 8 weeks; lipase, $55.3 \pm 36 \mathrm{IU} / \mathrm{L}$ at 0 weeks versus $43.8 \pm 14.9 \mathrm{IU} / \mathrm{L}$ at 8 weeks), but the differences were not significant (Figure 1).

At 8 weeks, pain alleviation after the low-fat ED therapy was reported in 15 of 17 patients (88\%). Of these 15 patients, 10 patients reported complete pain disappearance. One of 2 patients whose pain did not improve had calcified CP accompanied with pancreatic atrophy indicative of the socalled late-stage CP. No patient experienced pain exacerbation after the low-fat ED therapy. The evaluation of pain using pain grades at 0,4 , and 8 weeks is shown in Figure 2. At the beginning of the low-fat ED therapy, pain severity was classified as grade 2 in 3 patients (18\%) and grade 1 in 14 patients $(82 \%)$. At 8 weeks, the number of patients with grade 2 and grade 1 decreased to 2 patients $(12 \%)$ and 5 patients $(29 \%)$, respectively.
Patients' mean serum levels of total protein and albumin at 8 weeks did not differ significantly from those at 0 weeks (total protein, $73.5 \pm 5.5 \mathrm{~g} / \mathrm{L}$ at 0 weeks versus $73.4 \pm 5.1 \mathrm{~g} / \mathrm{L}$ at 8 weeks; albumin, $46.3 \pm 3.0 \mathrm{~g} / \mathrm{L}$ at 0 weeks versus $44.4 \pm 3.1 \mathrm{~g} / \mathrm{L}$ at 8 weeks).

\section{Discussion}

$\mathrm{CP}$ is often associated with recurrent or protracted pain that impairs quality of life [1-3]. The pathogenesis of pain generation in CP remains incompletely understood despite considerable research [12]. The most potential source of pain in CP is increased pressure within the pancreatic ducts and tissues resulting from the hyperstimulation of exocrine pancreatic secretion, pancreatic stones, or strictures of the pancreatic duct $[13,14]$. Fat intake induces the release of cholecystokinin (CCK) in the duodenum, which stimulates secretions from the pancreatic exocrine gland [15]. Therefore, it is theoretically reasonable to restrict oral fat intake to prevent painful relapses. Indeed, a low-fat enteral supplement has been shown to minimally increase plasma CCK levels, leading to reduced postprandial pain in CP [16].

$\mathrm{ED}$ is a digested nutritional supplement that consists of amino acids, dextrin or glucose, and minimal fat. A few reports have shown that $\mathrm{ED}$ was useful in the management of pancreatitis since it is less simulating to the pancreas $[5,17,18]$. In particular, the Elental preparation used in the present study contains an extremely small amount of fat $(0.17 \mathrm{~g} / 100 \mathrm{kcal})$. Pain reduction was seen in $88 \%$ of $\mathrm{CP}$ patients on low-fat ED therapy in addition to dietary fat restriction. Moreover, 1 of 3 patients with severe or moderate pain requiring an analgesic was relieved of the analgesic use after low-fat ED therapy. Although the precise mechanism by which low-fat ED therapy exerts the therapeutic efficacy for pain in CP is unknown, it is postulated that this therapy may enhance the efficacy of restricting fat intake in meals and reduce pain by decreasing the release of CCK.

Enteral nutrition therapy using ED was reported to have supportive effects in patients with Crohn's disease, including the remission of active disease, maintaining the remission of quiescent disease, and preventing postoperative recurrence $[5,19]$. These supportive effects are thought to be associated with improved bacterial flora, low antigenicity, and improved nutritional status [20,21]. Meanwhile, some reports have suggested that amino acids such as glutamine, glycine, and histamine have an anti-inflammatory effect on animal experimental and human chronic inflammatory disease [2226]. Therefore, the abundant amino acids within ED might directly alleviate pancreatic inflammation and lead to pain relief. This hypothesis has yet to be verified.

Nutrition support is considered important in the management of CP because patients suffering from CP sometimes experience maldigestion due to pancreatic exocrine insufficiency resulting from ongoing pancreatic destruction [1]. Another advantage of ED is that the formula consists mainly of amino acids and dextrin, which do not require pancreatic enzymes for digestion and absorption. Therefore, ED is expected to offer optimal nutrition support even in 


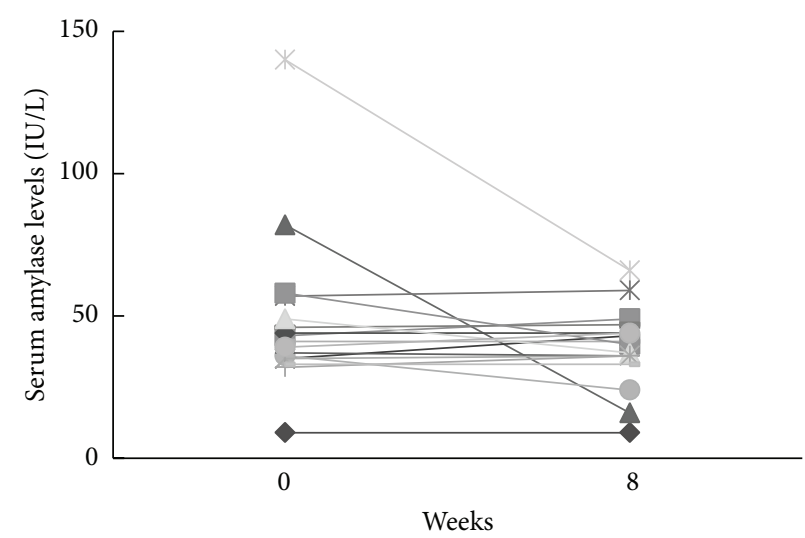

(a)

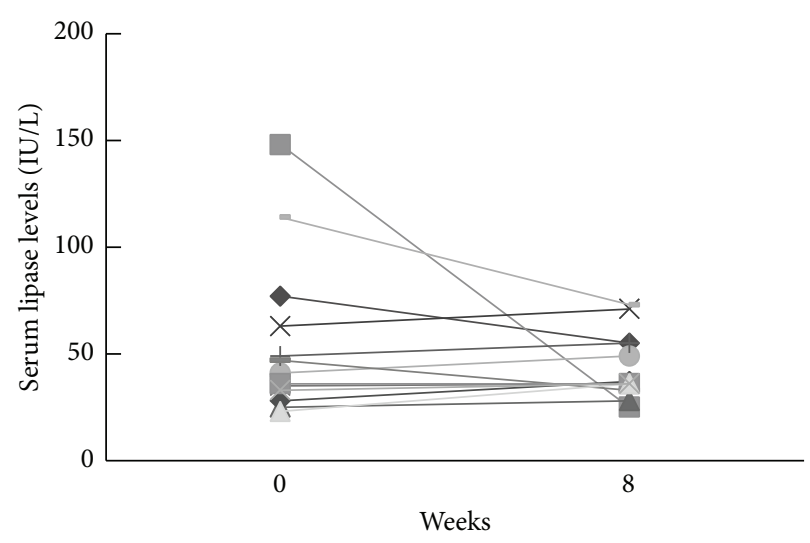

(b)

FIGURE 1: Serum levels of amylase and lipase at 0 and 8 weeks after low-fat ED therapy. (a) Amylase. (b) Lipase.

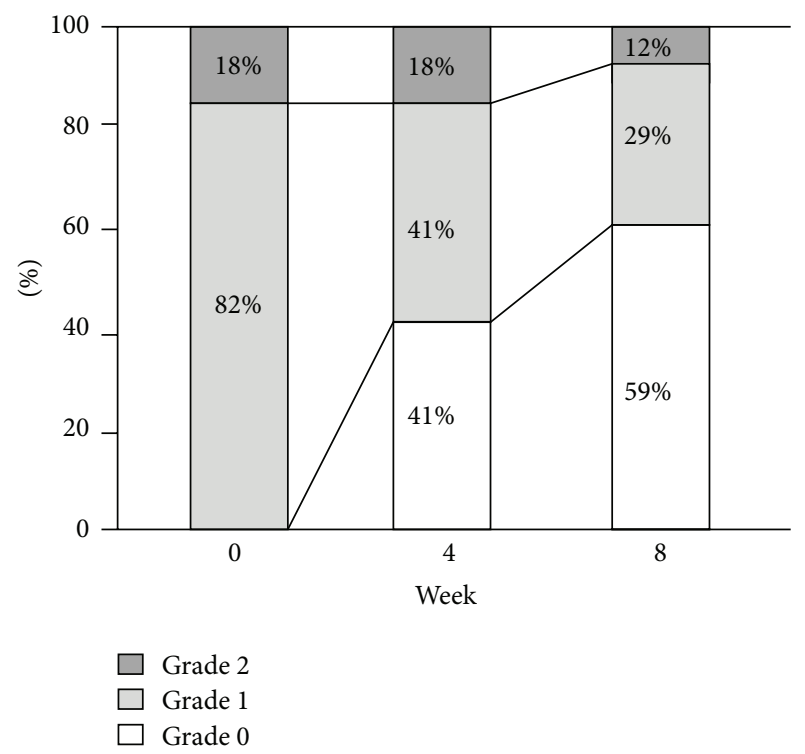

FIGURE 2: Evaluation of pain using pain grades at 0,4 , and 8 weeks.

patients with $\mathrm{CP}$ who have severe exocrine insufficiency. In this study, the use of ED had no influence on nutritional parameters such as serum levels of total protein and albumin. The reason for this is that most of the patients included in this study had good nutrition because of pancreatic exocrine sufficiency or the administration of pancreatic enzymes.

Ito et al. reported 2 cases of calcified $\mathrm{CP}$ with repeated pain episodes that could be alleviated using low-fat ED therapy [6]. In this study, only $12 \%$ of the patients had calcified $\mathrm{CP}$, which was diagnosed as definite $\mathrm{CP}$ according to Japanese diagnostic criteria. Pancreatic pain tends to be seen more frequently in the early stage rather than in the late stage of CP [27]. Since the pain observed in patients with late-stage $\mathrm{CP}$ is frequently caused by pancreatic stones, endoscopic and surgical intervention is often required. The results of this study indicate that low-fat ED therapy is more effective for patients with early-stage CP than for patients with late-stage CP.

To date, several attempts have been made to evaluate the degree of pain in $\mathrm{CP}$ using different pain scales and protocols (e.g., a visual analogue scale) $[28,29]$. However, it is difficult to accurately evaluate pain intensity since the individual perception of pain varies among patients. A standard means for evaluating the utility of pain treatment is still lacking [28]. In this study, in addition to interviewing each patient, the pain degree was classified into 3 grades based on the presence or absence of analgesics use to make it easier to evaluate the degree of pain.

Low-fat ED therapy is safe and simple. However, a patient suffering from diabetes had to abandon ED therapy at 4 weeks due to aggravated glycemic control. Particular attention is needed when administering ED therapy to patients with $\mathrm{CP}$ and diabetes.

In summary, low-fat ED therapy might be useful for pain management of outpatients with $\mathrm{CP}$ when patients experience acute and recurring pain attacks. The results of this study need to be confirmed by a randomized study comparing pain control responses between patients with $\mathrm{CP}$ who are or are not treated with low-fat ED therapy.

\section{Conflict of Interests}

The authors declare that there is no conflict of interests regarding the publication of this paper.

\section{References}

[1] M. L. Steer, I. Waxman, and S. Freedman, "Chronic pancreatitis," The New England Journal of Medicine, vol. 332, no. 22, pp. 1482-1490, 1995.

[2] B. Etemad and D. C. Whitcomb, "Chronic pancreatitis: diagnosis, classification, and new genetic developments," Gastroenterology, vol. 120, no. 3, pp. 682-707, 2001.

[3] P. G. Lankisch, "Natural course of chronic pancreatitis," Pancreatology, vol. 1, no. 1, pp. 3-14, 2001. 
[4] American Gastroenterological Association Medical Position Statement, "Treatment of pain in chronic pancreatitis," Gastroenterology, vol. 115, no. 3, pp. 763-764, 1998.

[5] T. Matsui, T. Sakurai, and T. Yao, "Nutritional therapy for Crohn's disease in Japan," Journal of gastroenterology, vol. 40, supplement 16, pp. 25-31, 2005.

[6] T. Ito, H. Igarashi, Y. Niina et al., "Management of pain in chronic pancreatitis with home elemental diet ingestion," Journal of the Pancreas, vol. 11, no. 6, pp. 648-649, 2010.

[7] C. Niederau and J. H. Grendell, "Diagnosis of chronic pancreatitis," Gastroenterology, vol. 88, no. 6, pp. 1973-1995, 1985.

[8] T. Shimosegawa, K. Kataoka, T. Kamisawa et al., "The revised Japanese clinical diagnostic criteria for chronic pancreatitis," Journal of Gastroenterology, vol. 45, no. 6, pp. 584-591, 2010.

[9] T. Yamamoto, M. Nakahigashi, S. Umegae, T. Kitagawa, and K. Matsumoto, "Impact of elemental diet on mucosal inflammation in patients with active Crohn's disease: cytokine production and endoscopic and histological findings," Inflammatory Bowel Diseases, vol. 11, no. 6, pp. 580-588, 2005.

[10] T. Kajiura, T. Takeda, S. Sakata et al., "Change of intestinal microbiota with elemental diet and its impact on therapeutic effects in a murine model of chronic colitis," Digestive Diseases and Sciences, vol. 54, no. 9, pp. 1892-1900, 2009.

[11] Definition and diagnosis of diabetes mellitus and intermediate hyperglycemia, Report of A WHO/IDF Consultation, World Health Organization, Geneva, Switzerland, 2006.

[12] T. Ikeura, Y. Kataoka, T. Wakabayashi et al., "Effects of sensory denervation by neonatal capsaicin administration on experimental pancreatitis induced by dibutyltin dichloride," Medical Molecular Morphology, vol. 40, no. 3, pp. 141-149, 2007.

[13] N. Ebbehøj, L. Borly, J. Bulow et al., "Pancreatic tissue fluid pressure in chronic pancreatitis. Relation to pain, morphology, and function," Scandinavian Journal of Gastroenterology, vol. 25, no. 10, pp. 1046-1051, 1990.

[14] P. Di Sebastiano, F. F. Di Mola, D. E. Bockman, H. Friess, and M. W. Büchler, "Chronic pancreatitis: the perspective of pain generation by neuroimmune interaction," Gut, vol. 52, no. 6, pp. 907-911, 2003.

[15] S. Watanabe, K. Shiratori, and T. Takeuchi, "Release of cholecystokinin and exocrine pancreatic secretion in response to an elemental diet in human subjects," Digestive Diseases and Sciences, vol. 31, no. 9, pp. 919-924, 1986.

[16] J. C. Shea, M. D. Bishop, E. M. Parker, A. Gelrud, and S. D. Freedman, "An enteral therapy containing medium-chain triglycerides and hydrolyzed peptides reduces postprandial pain associated with chronic pancreatitis," Pancreatology, vol. 3, no. 1, pp. 36-40, 2003.

[17] H. Ragins, S. M. Levenson, and R. Signer, "Intrajejunal administration of an elemental diet at neutral $\mathrm{pH}$ avoids pancreatic stimulation: studies in dog and man," American Journal of Surgery, vol. 126, no. 5, pp. 606-614, 1973.

[18] A. Voitk, R. A. Brown, V. Echave, A. H. McArdle, F. N. Gurd, and A. G. Thompson, "Use of an elemental diet in the treatment of complicated pancreatitis," The American Journal of Surgery, vol. 125 , no. 2, pp. 223-227, 1973.

[19] T. Yamamoto, M. Shiraki, M. Nakahigashi, S. Umegae, and K. Matsumoto, "Enteral nutrition to suppress postoperative Crohn's disease recurrence: a five-year prospective cohort study," The International Journal of Colorectal Disease, vol. 28, no. 3, pp. 335-340, 2013.
[20] K. Teahon, P. Smethurst, M. Pearson, A. J. Levi, and I. Bjarnason, "The effect of elemental diet on intestinal permeability and inflammation in Crohn's disease," Gastroenterology, vol. 101, no. 1, pp. 84-89, 1991.

[21] K. Teahon, M. Pearson, T. Smith, and I. Bjarnason, "Alterations in nutritional status and disease activity during treatment of Crohn's disease with elemental diet," Scandinavian Journal of Gastroenterology, vol. 30, no. 1, pp. 54-60, 1995.

[22] C. K. Ameho, A. A. Adjei, E. K. Harrison et al., "Prophylactic effect of dietary glutamine supplementation on interleukin 8 and tumour necrosis factor $\alpha$ production in trinitrobenzene sulphonic acid induced colitis," Gut, vol. 41, no. 4, pp. 487-493, 1997.

[23] I. Tsune, K. Ikejima, M. Hirose et al., "Dietary glycine prevents chemical-induced experimental colitis in the rat," Gastroenterology, vol. 125, no. 3, pp. 775-785, 2003.

[24] A. Andou, T. Hisamatsu, S. Okamoto et al., "Dietary histidine ameliorates murine colitis by inhibition of proinflammatory cytokine production from macrophages," Gastroenterology, vol. 136, no. 2, pp. 564.e2-574.e2, 2009.

[25] R. S. Pinals, E. D. Harris, J. B. Burnett, and D. A. Gerber, "Treatment of rheumatoid arthritis with L-histidine: a randomized, placebo-controlled, double-blind trial," The Journal of Rheumatology, vol. 4, no. 4, pp. 414-419, 1977.

[26] M. Watanabe, M. E. Suliman, A. R. Qureshi et al., "Consequences of low plasma histidine in chronic kidney disease patients: associations with inflammation, oxidative stress, and mortality," American Journal of Clinical Nutrition, vol. 87, no. 6, pp. 1860-1866, 2008.

[27] R. W. Ammann, B. Muellhaupt, A. Akovbiantz et al., "The natural history of pain in alcoholic chronic pancreatitis," Gastroenterology, vol. 116, no. 5, pp. 1132-1140, 1999.

[28] H. G. Beger, W. Krautzberger, and R. Bittner, "Duodenumpreserving resection of the head of the pancreas in patients with severe chronic pancreatitis," Surgery, vol. 97, no. 4, pp. 467-473, 1985.

[29] B. Glasbrenner and G. Adler, "Evaluating pain and the quality of life in chronic pancreatitis," International Journal of Pancreatology, vol. 22, no. 3, pp. 163-170, 1997. 


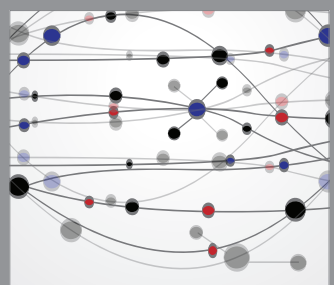

The Scientific World Journal
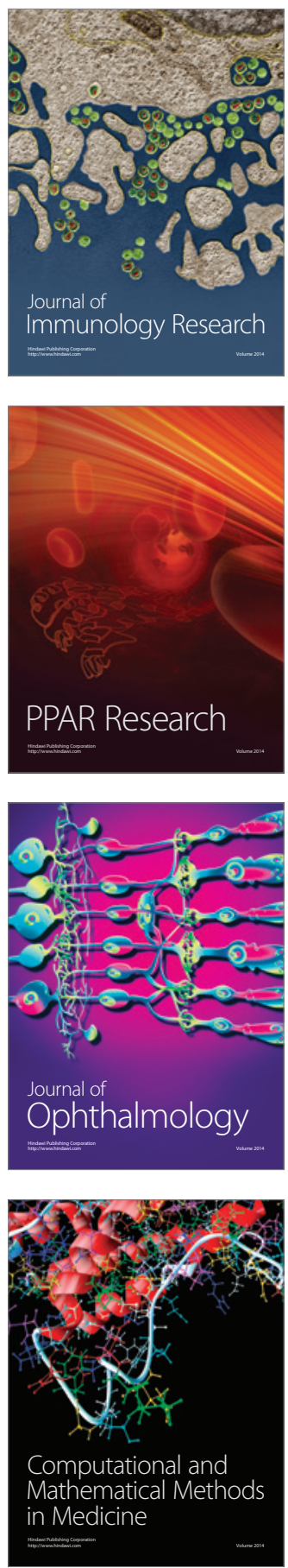

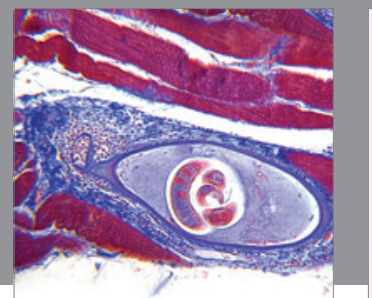

Gastroenterology

Research and Practice
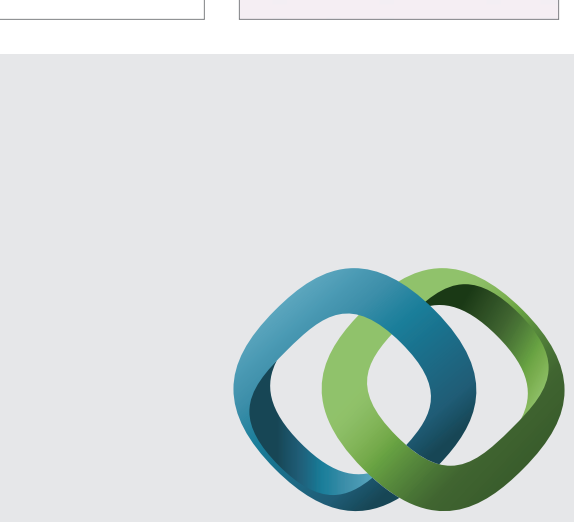

\section{Hindawi}

Submit your manuscripts at

http://www.hindawi.com
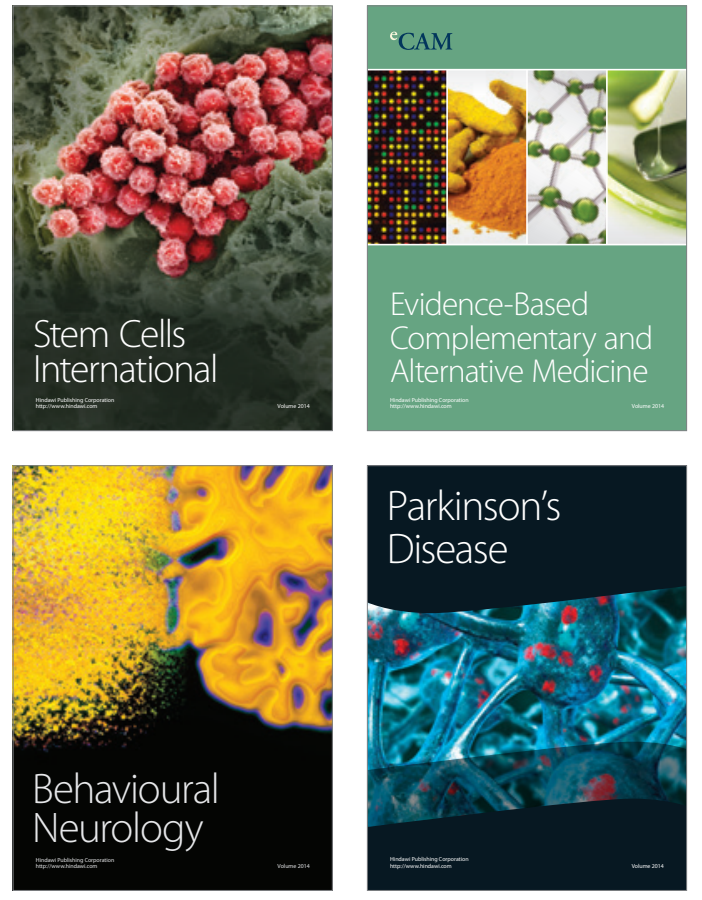
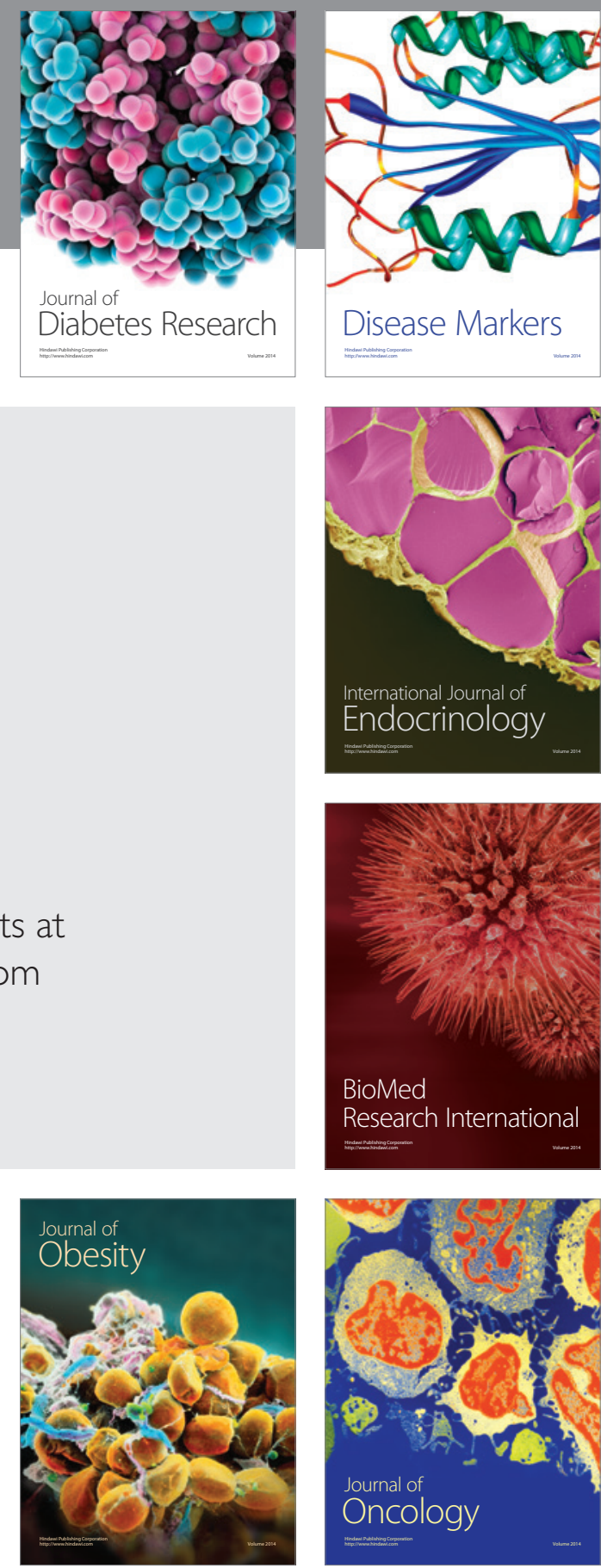

Disease Markers
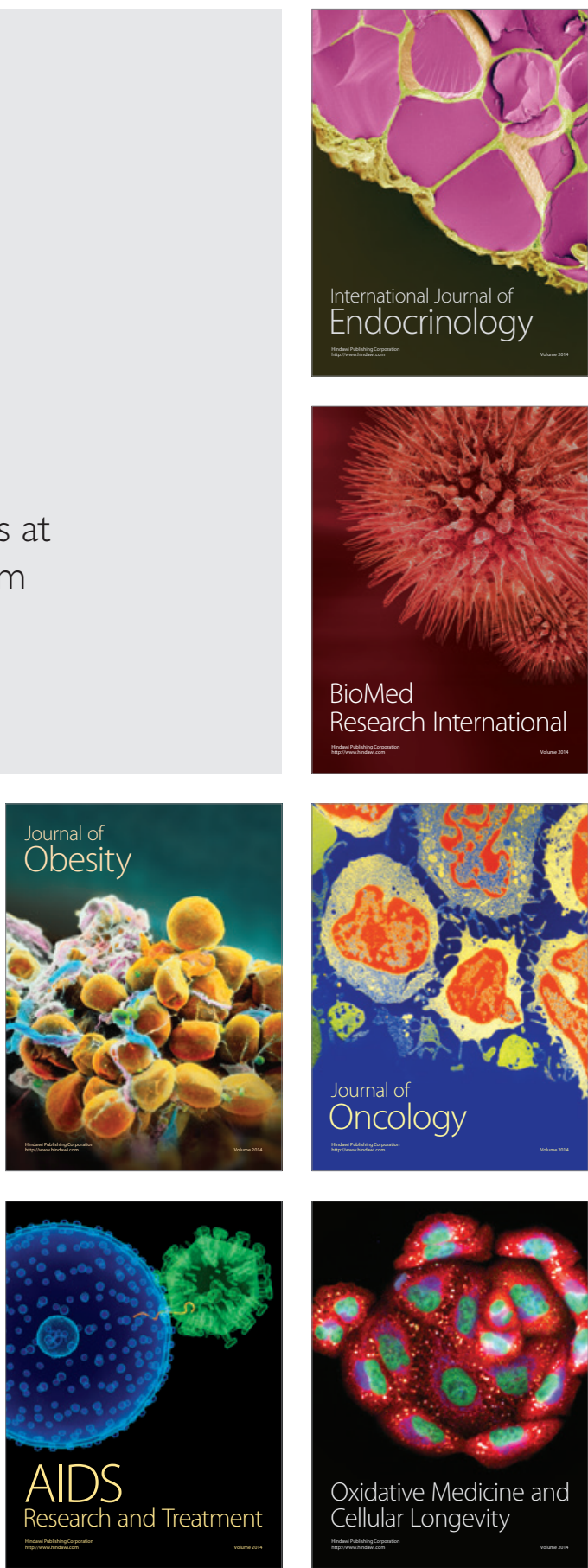